\title{
Formation of University Students' Readiness for Parenthood
}

\author{
Gulnara F. Biktagirova ${ }^{1}$ \& Roza A. Valeeva ${ }^{1}$ \\ ${ }^{1}$ Kazan (Volga region) Federal University, Kazan, Russia \\ Correspondence: Gulnara F. Biktagirova, Kazan (Volga region) Federal University, Kremlyovskaya Street 18, \\ Kazan, 420008, Russia.
}

Received: December 29, 2014

Accepted: January 22, 2015 Online Published: February 11, 2015

doi:10.5539/res.v7n4p93

URL: http://dx.doi.org/10.5539/res.v7n4p93

\begin{abstract}
Forming students' readiness for family life involves the formation of their readiness for responsible parenthood. The aim of the study was the theoretical basis and experimental testing of the training program to form the students' readiness for parenthood. The article deals with the relevance of the problem, defining parenting in psychological, educational, social and philosophical literature, the study of the problem in Russia, research methodology and experimental study on the issue. During the research we have developed and tested a training program. The results of pedagogical experiment allow to come to the conclusion about the effectiveness of the developed program "I am a Future Parent".
\end{abstract}

Keywords: parenting, readiness for parenthood, the formation of readiness for parenthood, students, family

\section{Introduction}

\subsection{Actualization of the Problem}

Family stability is a prerequisite for the society and the individual development. Today's Russia is unfortunately characterized by the change of the family foundations, demographic situation and the youth attitude towards parenthood. According to Russian scientists Ovcharova (2006) and Ermikhina (2004), school and university students do not have clear ideas about parenting. Young people's ideas about parenting system are on the stage of formation and are not completely understood. Therefore, one of the priority-oriented guidelines of practical psychological education development in Russia is the formation of the special readiness for conscious responsible parenthood, as almost everyone becomes a parent, and the quality of up-bringing, marital interaction depends on the state of parenthood in the family.

\subsection{Explore Importance of the Problem}

In this regard, the education system faces the task of forming an appropriate system of students' values, providing prestige of family life, a positive image of the family; a stable ideal of officially registered marriage; responsible parenthood up-bringigng from a young age. Parenting plays a significant role in the life of a particular individual. Throughout his life, the parent remains a significant figure for everybody. Under these conditions, higher education is now becoming not only a professional institution, it becomes a mechanism of formation of the young people's general culture, their readiness for normal stable life, moral self-regulation, the strategic design of the vector of the vital way including parenthood, regardless of the profile of training (Biktagirova, 2013) . Educational institutions should be an important element in the state social policy aiming on strengthening families, and help to develop students' readiness for family life and the performance of the parents' functions.

\subsection{The Concept of "Parenthood"}

The phenomenon of parenthood is a subsystem in the family system, as a relatively independent unit. We consider the "parenting" as a socio-psychological phenomenon, including the emotional and evaluative colored body of knowledge, as well as perceptions and beliefs about you as a parent and implemented in all aspects of the behavioral component of parenting. It includes both spouses who have decided to start a new life. Parenting as a psychological phenomenon is a complex structure that Ovcharova offers to consider from the point of view of the system and phenomenological approaches (Ovcharova, 2008).

Readiness for parenthood is determined not only by physiological and moral factors, but the ability of a person to understand his actions and desires, the ability to set goals, adopted in society and the family. As a result a commitment to up-bringing a child appears. 


\subsection{Status of a Problem}

Problems of parenthood study in Russia is most clearly designated in the works of Kon (1988). Ovcharova (2006) and Gurko (2008). Already in the 80 -ies I. Kon conducted a research, analyzing the foreign papers within the so called main stream (Walters \& Walters, 1980), as a well-established direction of research according to the theory of family development (development approach) (Minton \& Pasley, 1996; Palkovitz, 1997). The development approach includes the idea of parental influence on the development of a child, the parents' experience of stress as children get older, and subsequent children appear, as well as the study of fatherhood and motherhood, and the ratio of family roles compared to professional roles (Kon, 2001). Later in the 90-s there were studies on the empirical level, which allowed parenting domain to stand in a separate study field; conceptual apparatus was refined; the main directions of empirical research were defined (Marsiglio, Roy, \& Fox, 2005). Nowadays the researches of Ermihina (2004) and Ivakin (2006) present the analysis of the general trends of the Institute of parenting, juvenile motherhood practices, social problems of parents in the crisis society, paternal behavior in different social groups, the distribution of parental responsibilities in the families with teenagers and in young families, maternity and paternity through the eyes of children and adolescents.

\subsection{Hypothesis of the Study}

Analysis of theoretical and practical teaching and research activities in the aspect of the developed problem showed that it is the understudied area of scientific knowledge and practical activities. This enabled to formulate hypotheses of the study: the level of youth's readiness for parenting would benefit if:

- It is formed on the knowledge of the basic concepts of "parenthood", "motherhood", "fatherhood" in shaping the students' perceptions about the readiness for parenthood;

- To take into account the young people's peculiarities of the ideas about motherhood and fatherhood development;

- To develop and test a training program forming students' readiness for parenthood "I am a Future Parent".

\section{Materials and Methods}

\subsection{The Tasks of the Research}

The study addressed the following objectives: 1) To analyze the psychological and pedagogical literature for the study of "parenthood" and "readiness for parenthood" notions; 2) To select the main factors of students' responsible parenthood forming; 3) To describe the training as means of students' readiness for parenting formation; 4)To develop and test a training program preparing students for parenthood "I am a Future Parent".

\subsection{Theoretical and Empirical Methods}

In compliance with the goal, the following methods have been selected:

- Theoretical: analysis of the pedagogical and psychological literature; study and generalization of innovative pedagogical experience, analysis, synthesis;

- Empirical: participant observation, ascertaining and forming pedagogical experiment, questionnaires, tests, interviews, conversations, learning outcomes of educational and extracurricular activities of students, as well as methods of mathematical statistics

\subsection{Base of the Study}

Pedagogical experiment on students' readiness for parenthood formation was held at the Institute of Psychology and Education, Kazan federal university from September 2013 to April 2014. The study involved young people aged 19 to 21 years old, 4th year students. The experiments were performed in vivo implementation of the educational process.

\subsection{Stages of the Study}

The study was conducted in three phases:

In the first stage the experimental platform at the Institute of Psychology and Education was created during the study of the discipline "Family pedagogy".

At the second stage, the pedagogical experiment was realized, the program was developed and special training was implemented in the educational process;

In the third stage, the classification and registration of the study materials took place, the results of the pedagogical experiment testing the effectiveness of the developed program were summarized. 


\subsection{Running and Description of the Experiment}

Formation of readiness for parenthood began with a definition of its main components:

- Cognitive: image of himself as a responsible person, the idea of the child as an equal member of the family, the idea of up-bringing as a positive development of personality rather than correcting its deficiencies;

- Behavioral: future parents' activity for care and financial security of the child, collaboration skills with the child (ability to talk about his feelings, to hear what he says, to resolve the conflict of the type "win-win");

- Axiological: unconditional acceptance of a family, child-parent relationship, the child as a value.

In the process of ascertaining stage of the experiment the cognitive component was detected by the method "Idea of the perfect parent" by Ovcharova (2006). The study of behavioral component was started with identification of readiness for parenthood level. We used Litvinova's test "Are you ready for parenthood?", aimed on identifying the entry-level of students' readiness for parenthood (Litvinova, 2005). It was found that low-level readiness for parenthood had $9.2 \%$ of students; $66.8 \%$ have an average level and only $24 \%$ - a high level of readiness for parenthood.

To determine the axiological component, we used the technique of value orientations by Rokeach (1973), the purpose of which is to identify the rank of instrumental and terminal values. By this method were identified structure of students' value orientations, and identified the leading value. Based on the data, we drew a conclusion that the students' most important terminal values are health, love and having friends. Happy family life is only in the 4th place, which means that most of the students are not yet ready to start a family and entry into adulthood.

According to this method the smaller the average values, the more important is the value. So at the very least is the average value of health - 4.14. This suggests that for students at this age it is important to be healthy. The second value is love- 4.48. As we know, it is the period when the students meet their soul mate, when they think about their happiness and the happiness of another person who will be next to him. Therefore, love occupies a significant place. The third point is having friends - 6.24. Without friends this age is empty and boring. According to data obtained in the course of ascertaining experiment, we can say that the students' readiness to parenthood is average. This is because it is important for them firstly to get an education and then only to think about starting a family. The students have an idea of what a family is and what it means for them, but it is a very serious step for them. Thus our goal is to help students to opt for a happy family life.

Experimental work was carried out in accordance with the identified problems and in accordance with our training program "I am a Future Parent". The main goal of it is the creation of conditions conducive to the formation of ideas about parenting, and the students' adequate positive parenthood skills. During the training technique role-playing game was used, when the students played the role of "a child" and "parents". They discussed with the participants of the training feelings arising in the course of playing the role; and received feedback about the quality of their behavior from the trainer and the participants.

\section{Results}

All participants expressed the interested attitude to the study and pedagogical experiment. The attitude to parenting, to a child, to understanding of parenting as an important part of family and difficulty of this process has changed. In addition, analyzing the data obtained, we found statistically significant differences $(p=0.02)$ only in representations of boys and girls on the cognitive component of the "perfect parent" image. Girls, compared with boys, attached greater importance to the cognitive component of parenthood, i.e. awareness of parents' kinship with children, the imagination of herself as a mother, the image of the spouse as a parent, parenting knowledge, the image of a child. On other components of the "ideal parent" image we haven't received significant differences between boys and girls.

Analysis of the data obtained after the control experiment to test "Are you ready for parenthood?" gave the following results, which are presented in the figure below (Figure 1.). 


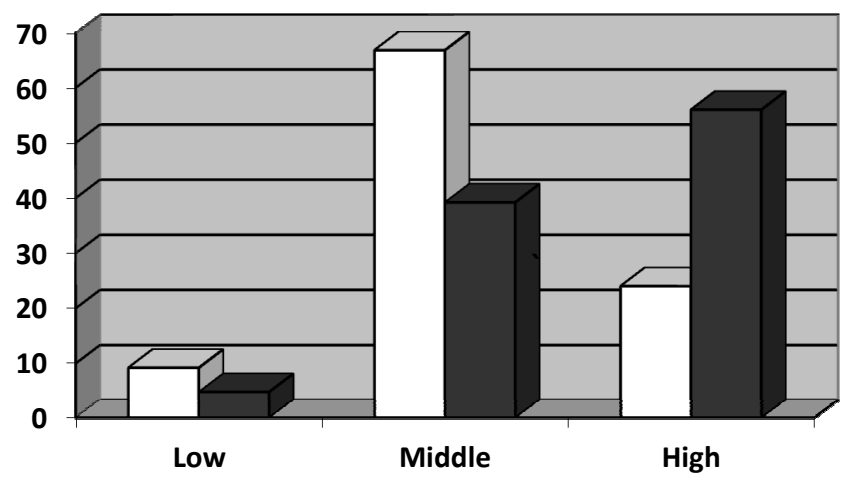

口Before

$\square$ After

Figure 1. Changes in the levels of students' readiness for parenthood before and after the experiment

Low level was still at $4.8 \%$ of the respondents, the average rate remained at $39.2 \%$ of the subjects. $56 \%$ of students are on a high level. Changes have occurred in value preferences (Figure 2).

After analyzing the data, we concluded that significant values were the same: health \& love. A happy family life moved from position 4 to 3 . This suggests that the developed program affected the students, and they rethought their views and happy family life has become more important and significant for them.

After the formative experiment by Student t-test, we obtained the following results:

1) The difference between the average level of students' readiness for parenting, before and after the experiment-reliable, since $\mathrm{t}_{\mathrm{emp}}>\mathrm{t}_{\mathrm{cr}}\left(\mathrm{t}_{\mathrm{emp}}=6.64,=2.00\right.$ at $\left.\mathrm{tkr} 1 ; \mathrm{t}_{\mathrm{kr}} 2=2.66\right)$ for $\mathrm{p}=0.01$;

2) The difference between the average values was not significant. But it was not the most important factor in our study, so we can say that, despite the partial confirmation of our hypothesis, the result has been received, and the experiment was a success.

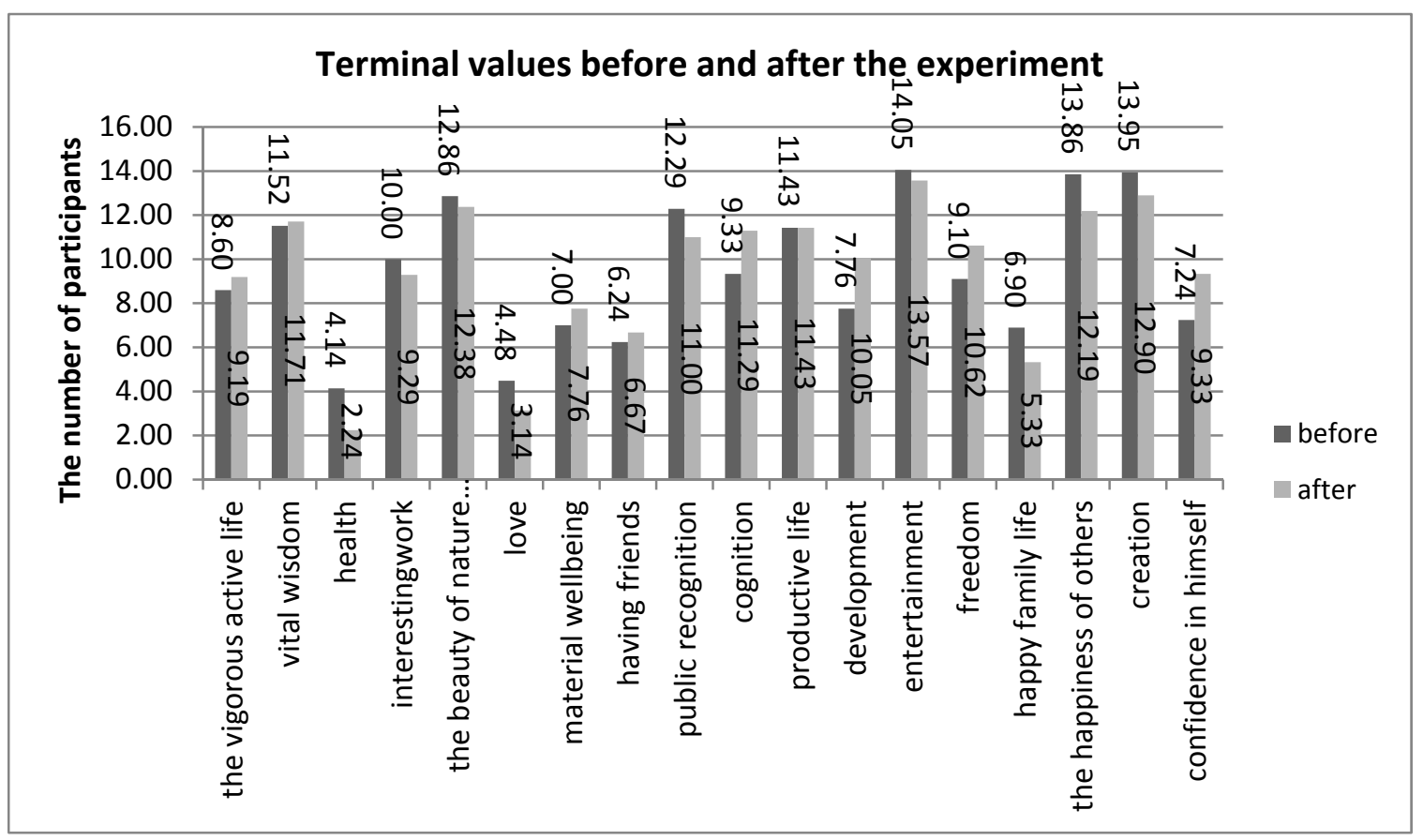

Figure 2. Students' terminal values before and after the experiment 


\section{Discussions}

The basic premise, which contributed to the formation of students' positive readiness for parenthood, was the necessity of its formation. Changes in cognitive and behavioral components indicate a change in relation to the notion of parenthood, children and readiness to become parents. Changes that have not been as significant in the axiological component can be explained that such changes can not happen, first, so quickly and, secondly, family value orientation in adolescence (the students aged 19-21) are not so relevant for students, their preferences a little bit different.

\section{Conclusion}

Thus, by analyzing and comparing the results of ascertaining and control stages of the pedagogical experiment, we can conclude that the developed training program "I am a Future Parent" is effective for the formation of students' readiness for parenting. The results of the training program showed a positive trend, and it demonstrates the effectiveness of the work organized.

\section{Acknowledgment}

The work is performed according to the Russian Government Program of Competitive Growth of Kazan Federal University

\section{References}

Biktagirova, G. (2013). Family traditions as they are viewed by contemporary Russian teenagers. Social and Behaviour Sciences (pp. 333-336). Proceedings of the 2nd International Congress on Interdisciplinary Behaviour and Social Sciences 2013. Jakarta, Indonesia.

Ermihina, M. O. (2004). Formation of responsible parenthood based on the subjective-psychological factors (Doctoral dissertation). Kazan: KSU

Gurko, T. A. (2008). Marriage and parenthood in Russia. Moscow: Institute of Sociology, Russian Academy of Sciences.

Ivakin, V. V. (2006). Formation of girl-students' psychological readiness for motherhood (Doctoral dissertation). Stavropol: SKGTU.

Kon, I. S. (1988). Child and Society. Moscow: Nauka.

Kon, I. S. (2001). Ethnography of Parenthood. Moscow: Higher School.

Litvinova, N. N. (2005). Pedagogical conditions of university students' survivors of domestic violence positive I-parent image formation. (Doctoral dissertation). Stavropol: SKGTUM.

Marsiglio, W., Roy K., \& Fox, G. L. (Eds.) (2005). Situated fathering: A focus on physical and social space. Rowman and Littlefield Publishers, Inc.

Minton, C. \& Pasley, K. (1996). Fathers' parenting role identity and father's involvement: A comparison of nondivorced and divorced, nonresident fathers. Journal of Family Issues, 17. http://dx.doi.org/10.1177/019251396017001003

Ovcharova, R. V. (2006). Parenthood as a psychological phenomenon. Moscow: MPSI.

Palkovitz, R. (1997). Reconstructing “involvement”: Expanding conceptualizations of men's caring in contemporary families. In A. J. Hawkins, \& D. C. Dollahite (Eds.), Generative fathering: Beyond deficit perspective. Thousand Oaks, CA: Sage.

Rokeach, M. (1973). The nature of human values. Free press, 5, 20-28.

Walters, J., \& Walters, L. (1980). Parent-child relationships: A review, 1970-1979. Journal of Marriage and the Family, 42(4). http://dx.doi.org/10.2307/351826

\section{Copyrights}

Copyright for this article is retained by the author(s), with first publication rights granted to the journal. This is an open-access article distributed under the terms and conditions of the Creative Commons Attribution license (http://creativecommons.org/licenses/by/3.0/). 